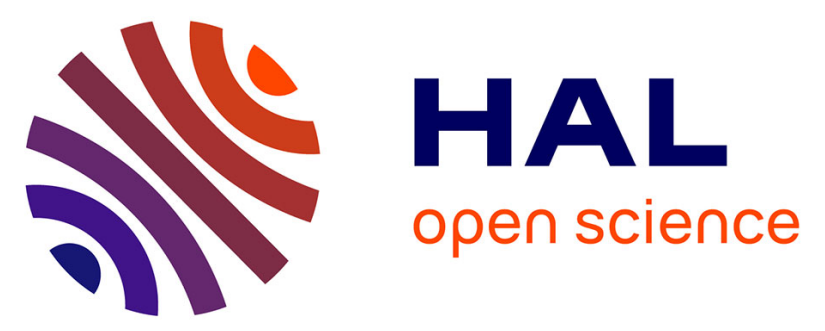

\title{
Bench Evaluation of Four Portable Oxygen Concentrators Under Different Conditions Representing Altitudes of 2438, 4200, and $8000 \mathrm{~m}$
}

Vincent Bunel, Amr Shoukri, Frederic Choin, Serge Roblin, Cindy Smith, Thomas Similowski, Capucine Morélot-Panzini, Jesus Gonzalez

\section{To cite this version:}

Vincent Bunel, Amr Shoukri, Frederic Choin, Serge Roblin, Cindy Smith, et al.. Bench Evaluation of Four Portable Oxygen Concentrators Under Different Conditions Representing Altitudes of 2438, 4200, and $8000 \mathrm{~m}$. High Altitude Medicine and Biology, 2016, 17 (4), pp.370 - 374. 10.1089/ham.2016.0056 . hal-01445040

\section{HAL Id: hal-01445040 \\ https: / hal.sorbonne-universite.fr/hal-01445040}

Submitted on 24 Jan 2017

HAL is a multi-disciplinary open access archive for the deposit and dissemination of scientific research documents, whether they are published or not. The documents may come from teaching and research institutions in France or abroad, or from public or private research centers.
L'archive ouverte pluridisciplinaire HAL, est destinée au dépôt et à la diffusion de documents scientifiques de niveau recherche, publiés ou non, émanant des établissements d'enseignement et de recherche français ou étrangers, des laboratoires publics ou privés. 
4

Bench evaluation of four portable oxygen concentrators under different conditions representing altitudes of 2,438, 4,200 and 8,000 meters.

(1)

Vincent Bunel ${ }^{1}$, Amr Shoukri ${ }^{2,3}$, Frederic Choin ${ }^{4}$, Serge Roblin ${ }^{4}$, Cindy Smith ${ }^{4}$, Thomas Similowski $^{1,2}$, Capucine Morélot-Panzini ${ }^{1,2}$, Jesus Gonzalez ${ }^{1,2}$

(1)

${ }^{1}$ AP-HP, Groupe Hospitalier Pitié-Salpêtrière Charles Foix, Service de Pneumologie et Réanimation Médicale (Département “R3S”), F-75013, Paris, France

2 Sorbonne Universités, UPMC Univ Paris 06, INSERM, UMRS1158 Neurophysiologie respiratoire expérimentale et clinique, Paris, France

${ }^{3}$ Shams University, Cairo, Egypt

${ }^{4}$ Service du centre d'essais d'AIRBUS Defence and Space, TSOEG25 - Components \& Synthesis Tests, Les Mureaux, France

(1)

Corresponding Author: Vincent Bunel, vincent.bunel@gmail.com

(1)

8

9




\section{Abstract}

Air travel is responsible for a reduction of the partial pressure of oxygen $\left(\mathrm{O}_{2}\right)$ as a result of the decreased barometric pressure. This hypobaric hypoxia can be dangerous for passengers with respiratory diseases, requiring initiation or intensification of oxygen therapy during the flight. In-flight oxygen therapy can be provided by portable oxygen concentrators, which are less expensive and more practical than oxygen cylinders, but no study has evaluated their capacity to concentrate oxygen under simulated flight conditions.

We tested four portable oxygen concentrators during a bench test study. The $\mathrm{O}_{2}$ concentrations $\left(\mathrm{FO}_{2}\right)$ produced were measured under three different conditions: in room air at sea level, under hypoxia due to a reduction of the partial pressure of $\mathrm{O}_{2}$ (normobaric hypoxia, which can be performed routinely) and under hypoxia due to a reduction of atmospheric pressure (hypobaric hypoxia, using a chamber manufactured by Airbus Defence and Space). The $\mathrm{FO}_{2}$ obtained under conditions of hypobaric hypoxia (chamber) was lower than that measured in room air (0.92 [0.89-0.92] versus $0.93[0.92-0.94], \mathrm{p}=0.029)$, but only one portable oxygen concentrator was unable to maintain an $\mathrm{FO}_{2} \geq 0.90(0.89$ [0.89-0.89]). In contrast, under conditions of normobaric hypoxia (tent) simulating an altitude of 2,438 m, none of the apparatuses tested was able to achieve an $\mathrm{FO}_{2}$ greater than $0.76 .(0.75[0.75-0.76]$ versus 0.93 [0.92-0.94], $\mathrm{p}=0.029)$.

Almost all portable oxygen concentrators were able to generate a sufficient quantity of $\mathrm{O}_{2}$ at simulated altitudes of $2,438 \mathrm{~m}$ and can therefore be used in the aircraft cabin. Unfortunately, verification of the reliability and efficacy of these devices in a patient would require a nonroutinely available technology and no pre-flight test can currently be performed by using simple techniques such as hypobaric hypoxia. 


\section{Keywords:}

54 - Equipment evaluation

55 - Chronic respiratory failure

56 - Ambulatory oxygen therapy

57 - Hypoxic challenge test

58 - Portable oxygen concentrator

59

60

61

62

63

64

65

66

67

68

69

70

71

72

73

74

75

76 
78 The minimum authorized pressure on commercial aircraft simulates an altitude of 8,000 feet (2,438 meters) for passengers. At this altitude, atmospheric pressure is decreased by about $25 \%$ compared to sea level, resulting in hypobaric hypoxia: the partial pressure of oxygen in inspired air corresponds to that observed on the ground during inhalation of a gas mixture containing $15 \%$ oxygen (Josephs et al., 2013). Although this hypobaric hypoxia has no consequences for passengers without respiratory diseases, it can be harmful in passengers with chronic respiratory diseases, who may require temporary oxygen therapy or more intensive continuous oxygen therapy (Ahmedzai et al., 2011).

Portable oxygen $\left(\mathrm{O}_{2}\right)$ concentrators are now approved by the Federal Aviation Administration (FAA) and consequently by all airlines (International Air Transport Association, 2015). They are increasingly used due to their considerable advantages in terms of cost, simplicity and safety compared to the oxygen cylinders conventionally provided by airline companies. Portable oxygen concentrators comprise a zeolite sieve, which binds nitrogen allowing the production of $\mathrm{O}_{2}$ according to a continuous mode or a pulsed mode (triggered by breathing, less energy-consuming). To our knowledge, only one study has tested the capacity of these apparatuses under hypoxic conditions, but under alpine conditions in COPD patients (Fischer et al., 2013). These apparatuses have never been evaluated on a test bench simulating hypoxia in an aircraft cabin. An hypoxic atmosphere is difficult, expensive and tedious to reproduce and often requires the assistance of military scientists (Dillard et al., 1995; Naughton et al., 1995). To address this issue, we verified whether portable oxygen concentrators were still able to generate $\mathrm{O}_{2}$ in an hypoxic atmosphere and then studied the possibility of testing these devices by means of a simpler hypoxia test. To answer these questions, we tested the oxygen concentrating capacities of four FAA-approved portable oxygen concentrators (Federal Aviation Administration, 2016) in the laboratory under 2 different conditions of simulated 
102 hypoxia: normobaric hypoxia and, more simply, hypobaric hypoxia, ((Dine and Kreider,

103 2008; Edvardsen et al., 2012; Kelly et al., 2008), as this method has been shown to be 104 equivalent to a hypobaric hypoxia test (Dillard et al., 1995; Dine and Kreider, 2008). These

105 two hypoxia conditions simulate different altitudes: 2,438 $\mathrm{m}$ (the lowest pressure authorized

106 in an aircraft cabin), and, by curiosity, we also tested a simulated altitude of 4,200 $\mathrm{m}$ (the

107 limit for the release of oxygen masks in flight) and 8,000 $\mathrm{m}$ (close to the summit of Mount 108 Everest).

\section{METHODS}

110 We conducted a bench test study on four FAA-approved portable oxygen concentrators: 111 SimplyGo (Philips Respironics Inc., Murrysville, PA, USA), Eclipse 3 (Chart Sequal 112 Technologies Inc., Ball Ground, GA, USA), Solo2 (Invacare Corporation, Elyria, OH, USA), 113 iGo (deVilbiss Healthcare Inc., Somerset, PA, USA).

114 The normobaric hypoxic test was performed with an hypoxic generator (decreasing $\mathrm{O}_{2}$ and 115 increasing nitrogen content) connected to an airtight tent (HYPOXICO Inc., Jalhay, Belgium).

116 The hypobaric hypoxic test was performed with an altitude chamber specifically designed in

117 order to test a portable oxygen concentrator, in collaboration with Airbus Defence and Space,

118 based on the principle of generating low pressure in the chamber by means of a rotary vane 119 pump and piloting the chamber with air renewal via a calibrated valve (Figure 1). The 120 targeted pressure, measured by an absolute pressure transducer, was 753 mbar (equivalent to 121 the atmospheric pressure at an altitude of $2,438 \mathrm{~m}$. This set-up was also used to perform tests 122 at 450 mbar (atmospheric pressure at 4,214 m) and 356 mbar (atmospheric pressure at 8,000 $123 \mathrm{~m})$. An airtight outlet tube from the chamber was used to reliably measure the $\mathrm{O}_{2}$ 124 concentration $\left(\mathrm{FO}_{2}\right)$, ( $\mathrm{MaxO}_{2}+$, MAXTEC Inc., Utah, USA). A special oxygen monitor that 125 can be used at low atmospheric pressure (Tetra 3, Crowcon Ltd, Abingdon, UK) was used to 126 ensure that the $\mathrm{FO}_{2}$ inside the chamber remained stable at 0.209. 
127 Each portable oxygen concentrator was tested first in room air (Airbus Defence and space

128 laboratory, altitude: $28 \mathrm{~m}$, atmospheric pressure: about $1000 \mathrm{mbar}$ ) and then under conditions

129 of normobaric hypoxia (tent) and hypobaric hypoxia (chamber). Measurements were

130 performed on the same day to limit variations in temperature, relative humidity and

131 atmospheric pressure that could influence the measurement. For each condition, we calculated

132 the median of $30 \mathrm{FO}_{2}$ measurements performed over 15 minutes in order to assess the stability

133 of $\mathrm{FO}_{2}$. Each portable oxygen concentrator was used in continuous mode, because the pulsed

134 mode did not allow reliable measurement of $\mathrm{FO}_{2}$, and at the possible maximum flow rate, in

135 order to simulate the most unfavorable situation for these apparatuses corresponding to a

136 worst-case scenario. All 3 concentrators were therefore tested at $31 / \mathrm{min}$, and one concentrator

137 (SimplyGo) was tested at 2 1/min.

138 Due to the non-normal distribution of the data, the results were expressed as median [q1-q3]

139 and differences between conditions were tested by a Mann-Whitney test.

\section{$140 \quad \underline{\text { RESULTS }}$}

141 Under conditions of hypobaric hypoxia (chamber), the $\mathrm{FO}_{2}$ obtained was lower than that 142 measured in room air $(0.92$ [0.89-0.92] versus 0.93 [0.92-0.94], $\mathrm{p}=0.029)$, but one of the four 143 apparatuses was unable to achieve an $\mathrm{FO}_{2} \geq 0.90(0.89$ [0.89-0.89]) (Table 1). At simulated

144 altitudes of 4,200 $\mathrm{m}$ and $8,000 \mathrm{~m}$ in the altitude chamber, none of the apparatuses was able to

145 maintain an $\mathrm{FO}_{2} \geq 0.9$, but three portable oxygen concentrators were still able to concentrate

$146 \mathrm{O}_{2}$ to achieve an $\mathrm{FO}_{2}$ of $0.88[0.88-0.90](\mathrm{p}=0.0498, \mathrm{n}=3)$ at a simulated altitude of $4,200 \mathrm{~m}$

147 and one portable oxygen concentrators achieved an $\mathrm{FO}_{2}$ of 0.83 [0.73-0.84] at 8,000 $\mathrm{m}$

148 (Figure 2). In contrast, under conditions of normobaric hypoxia (tent) simulating an altitude

149 of $2,438 \mathrm{~m}$, none of the apparatuses tested was able to achieve an $\mathrm{FO}_{2}$ greater than 0.76 .

150 Overall, $\mathrm{FO}_{2}$ was 0.17 lower than that measured in room air $(0.75[0.75-0.76]$ versus 0.93 
151 [0.92-0.94], $\mathrm{p}=0.029$ ). As indicated by the interquartile range, $\mathrm{FO}_{2}$ measurements remained

152 stable over the 15-minute test period regardless of the condition tested.

\section{DISCUSSION}

154 Measurements performed in an altitude chamber showed that the majority of portable oxygen

155 concentrators tested achieved lower but satisfactory $\mathrm{FO}_{2}$ under hypobaric hypoxia equivalent

156 to the minimum pressure authorized in an aircraft cabin.

157 Our study confirms the results of a previous study conducted in an alpine environment that 158 demonstrated the capacity of portable oxygen concentrators to produce $\mathrm{FO}_{2}$ greater than 0.94

159 at altitudes of up to $3,250 \mathrm{~m}$ (Fischer et al., 2013). Our simulator showed that $\mathrm{O}_{2}$ production 160 was still possible at 4,000 $\mathrm{m}$ and $8,000 \mathrm{~m}$ with some portable oxygen concentrators, which

161 could be useful in contexts such as alpine rescues or hot-air balloons. Portable oxygen

162 concentrators are effectively able to concentrate $\mathrm{O}_{2}$ even under conditions of hypobaric 163 hypoxia, as all 4 apparatus tested comprise an air compressor before the air enters the zeolite 164 cylinders.

165 However, under simulated conditions of hypobaric hypoxia, the performance of the portable 166 oxygen concentrators was lower than that previously reported (Fischer et al., 2013) and one of 167 the portable oxygen concentrators was unable to generate an $\mathrm{FO}_{2}$ greater than the 168 recommended 0.90 to be classified as an "oxygen concentrator" (ISO 80601-2-69:2014).

169 These discordant results could be due to the fact that our simulation more closely resembled 170 the conditions of air travel than those of previously published tests or that this new generation 171 of portable oxygen concentrators is less efficient than those previously tested (Fischer et al., 172 2013). The fact that none of the oxygen concentrators was able to generate an $\mathrm{FO}_{2}$ greater 173 than 0.94 at sea level (Table 1) tends to suggest the decreased performance of this new 174 generation of portable oxygen concentrators, possibly related to miniaturization. However, all 175 of the apparatuses tested were FAA-approved (Federal Aviation Administration, 2016). It 
should be noted that FAA approval does not comprise any recommendation to test the $\mathrm{FO}_{2}$

177 under in-flight conditions, although such testing is implied as portable oxygen concentrators 178 are defined as "small, portable devices that work by separating oxygen from nitrogen and other gasses in the air and providing the user with oxygen at a concentration of more than 90 percent" (US Department of Transportation - Federal Aviation Administration, 2016).

181 Consequently, in order to reassure users, the capacity of a portable oxygen concentrator to

182 concentrate $\mathrm{O}_{2}$ under the hypoxic conditions of altitude should be tested prior to authorization 183 of the use of the device in the aircraft cabin, even when FAA approval has been obtained. 184 Unfortunately, the present study shows that testing under conditions of hypobaric hypoxia 185 would require excessively complex technology (compressor, resistant chamber, adapted 186 transducers) and we had to seek the assistance of space and military research (Airbus Defence 187 and Space), as in other countries (Dillard et al., 1995; Naughton et al., 1995). In view of these 188 constraints, we tried to validate a simpler test, such as the normobaric hypoxia test, which can 189 be performed routinely or even with a patient, but, unfortunately, this test provided inaccurate 190 measurements. The inability of portable oxygen concentrators to achieve satisfactory $\mathrm{FO}_{2}$ in 191 the tent could be due to an excessively high nitrogen concentration in the gas mixture used, as 192 functioning of portable oxygen concentrators is based on the principle of rapid pressure193 modulated adsorption of nitrogen on a zeolite molecular sieve, the capacity of which may be 194 insufficient under the conditions tested here.

195 Verification of the efficacy of the device and/or titration of the $\mathrm{O}_{2}$ flow rate before a flight 196 therefore cannot be performed by an hypoxia test with the currently available portable oxygen 197 concentrators, which raises an additional doubt concerning the value of pre-flight hypoxia 198 tests (Howard, 2013; Naeije, 2000), as recommended and performed at the present time 199 (Ahmedzai et al., 2011). We know that titrating supplemental oxygen during a hypoxia 200 challenge test is uncertain due to accumulation of $\mathrm{O}_{2}$ under the face mask (Akerø et al., 
2011). We also know that the HCT is good to predict in-flight $\mathrm{PaO}_{2}$, but not in-

202 flight symptoms (Edvardsen et al., 2013). Therefore, the recommendation to give $21 / \mathrm{min}$ of supplemental oxygen in-flight is in most cases could be the only practical choice.

These results place the physician in a difficult situation, as IATA international requirements

(International Air Transport Association, 2015) specify that "the passenger has talked with

his/her physician regarding fitness to fly and the requirement that an individual who wishes

to use a portable oxygen concentrator provide a written statement signed by a licensed physician that verifies that: The passenger is able to operate the device and to respond to any alarms. The treating physician has prescribed the oxygen flow rate”. A potential clinical

solution would be to prescribe the highest flow rate of the portable oxygen concentrator and

to encourage patients to titrate the necessary flow rate by means of a pulse oximeter during

212 the flight, especially in order to lower the flow rate and prolong the battery life, but this method could be anxiogenic and, most importantly, a pre-flight test cannot formally guarantee

214 the inflight efficacy of the portable oxygen concentrator. Under these conditions and in view 215 of the results obtained with our simulator, manufacturers should be required to provide 216 technical validation of portal oxygen concentrators proposed for air travel under conditions of 217 hypobaric hypoxia, especially by verifying the capacity to produce a $\mathrm{FO}_{2} 90 \%$ in flight.

218 In conclusion, our study shows that some but not all portable oxygen concentrators are able to 219 concentrate oxygen under conditions of altitude-related hypoxia and, as this study also 220 demonstrates that flight conditions with a portable oxygen concentrator cannot be easily 221 reproduced on the ground without a disproportionate use of technology, manufacturers should 222 be required to verify the efficacy of the portable oxygen concentrator by means of a hypobaric 223 hypoxia test before proposing their apparatus for use in an aircraft cabin. 
227 Ahmedzai, S., Balfour-Lynn, I.M., Bewick, T., Buchdahl, R., Coker, R.K., Cummin, A.R., 228 Gradwell, D.P., Howard, L., Innes, J.A., Johnson, A.O.C., et al. (2011). Managing passengers 229 with stable respiratory disease planning air travel: British Thoracic Society recommendations. 230 Thorax 66, i1-i30.

231 Akerø, A., Edvardsen, A., Christensen, C.C., Owe, J.O., Ryg, M., and Skjønsberg, O.H. 232 (2011). COPD and air travel: oxygen equipment and preflight titration of supplemental 233 oxygen. Chest $140,84-90$.

234 Dillard, T.A., Moores, L.K., Bilello, K.L., and Phillips, Y.Y. (1995). The preflight evaluation. 235 A comparison of the hypoxia inhalation test with hypobaric exposure. Chest 107, 352-357.

236 Dine, C.J., and Kreider, M.E. (2008). HYpoxia altitude simulation test*. Chest 133, 1002$237 \quad 1005$.

238 Edvardsen, A., Akerø, A., Christensen, C.C., Ryg, M., and Skjønsberg, O.H. (2012). Air 239 travel and chronic obstructive pulmonary disease: a new algorithm for pre-flight evaluation. 240 Thorax 67, 964-969.

241 Edvardsen, A., Ryg, M., Akerø, A., Christensen, C.C., and Skjønsberg, O.H. (2013). COPD 242 and air travel: does hypoxia-altitude simulation testing predict in-flight respiratory 243 symptoms? Eur. Respir. J. 42, 1216-1223.

244 Federal Aviation Administration (2016). Acceptance Criteria for Portable Oxygen 245 Concentrators Used On Board Aircraft. 
246 Fischer, R., Wanka, E.R., Einhaeupl, F., Voll, K., Schiffl, H., Lang, S.M., Gruß, M., and 247 Ferrari, U. (2013). Comparison of portable oxygen concentrators in a simulated airplane 248 environment. Respiratory Medicine 107, 147-149.

249 Howard, L.S. (2013). Last call for the flight simulation test? Eur. Respir. J. 42, 1175-1177.

250 International Air Transport Association (2015). Guidance on Managing Medical Events ISBN 251 978-92-9252-698-6 ㄷ.

252 Josephs, L.K., Coker, R.K., Thomas, M., BTS Air Travel Working Group, and British 253 Thoracic Society (2013). Managing patients with stable respiratory disease planning air 254 travel: a primary care summary of the British Thoracic Society recommendations. Prim Care 255 Respir J 22, 234-238.

256 Kelly, P.T., Swanney, M.P., Seccombe, L.M., Frampton, C., Peters, M.J., and Beckert, L. 257 (2008). Air travel hypoxemia vs. the hypoxia inhalation test in passengers with COPD. Chest $258 \quad 133,920-926$.

259 Naeije, R. (2000). Preflight medical screening of patients. Eur. Respir. J. 16, 197-199.

260 Naughton, M.T., Rochford, P.D., Pretto, J.J., Pierce, R.J., Cain, N.F., and Irving, L.B. (1995). 261 Is normobaric simulation of hypobaric hypoxia accurate in chronic airflow limitation? Am. J. 262 Respir. Crit. Care Med. 152, 1956-1960.

263 US Department of Transportation - Federal Aviation Administration (2016). Portable oxygen 264 concentrators - AC 120-95. 
271 There is no financial and non-financial competing interests for any authors of this manuscript.

273 Authors' contributions

274 Conception and design: VB, AS, FC, SR, CS, CMP, JG

275 Analysis and interpretation: VB, TS, JG

276 Drafting the manuscript for important intellectual content: VB, TS, JG

278 Acknowledgments:

279 Caroline Sevoz-Couche for contacts with AIRBUS Defence and Space.

280 Dr Vincent Feuillie, Medical VP, Air France for in-flight recommendations

281 François Thomassin, Afnor, for ISO recommendations 


\section{$\underline{\text { FIGURES }}$}

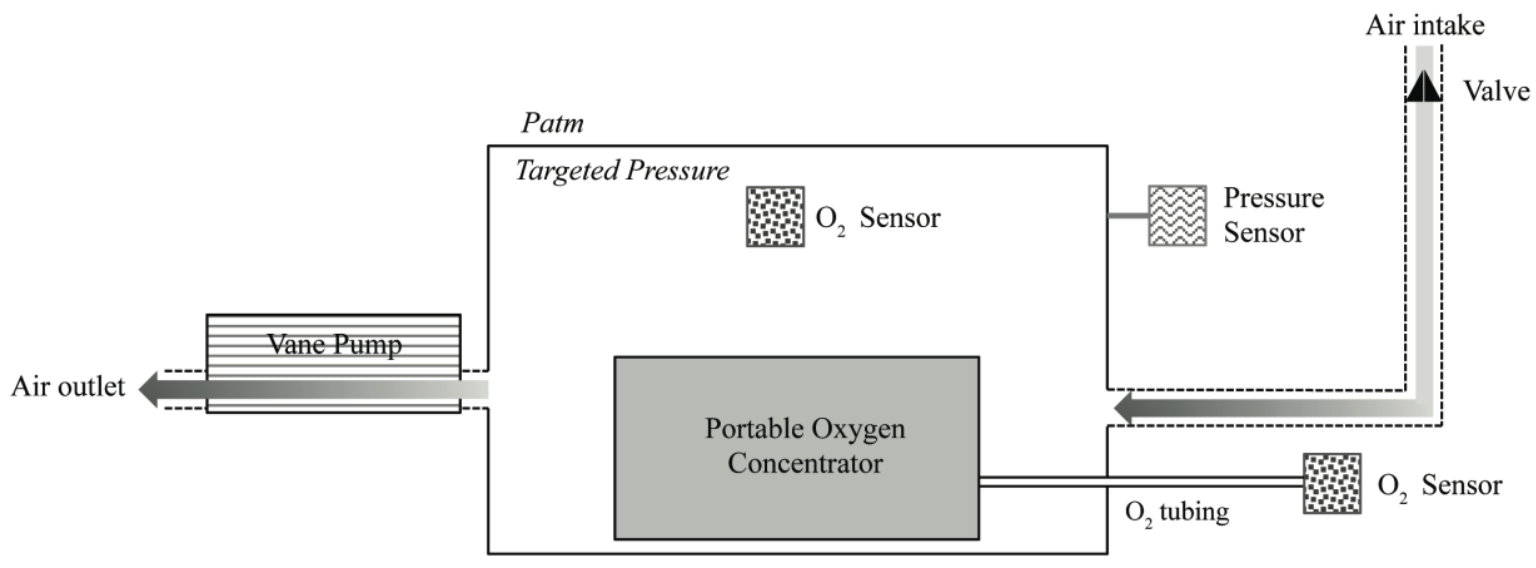

Tank

286 Figure 1: Description of the hypoxic chamber.

287 Generation of low pressure (targeted pressure) in the chamber by means of a rotary vane

288 pump and piloting the chamber with air renewal via a calibrated valve. The target pressure $\mathrm{P}$,

289 was measured by an absolute pressure transducer. An airtight outlet tube from the chamber

290 was used to reliably measure the $\mathrm{O}_{2}$ concentration, $\left(\mathrm{MaxO}_{2}+, \mathrm{MAXTEC}\right.$ Inc., Utah, USA). A

291 special oxygen monitor that can be used at low atmospheric pressure (Tetra 3, Crowcon Ltd,

292 Abingdon, UK) was used to ensure that the $\mathrm{FO}_{2}$ inside the chamber remained stable at 0.209.

293 Patm: atmospheric pressure. 

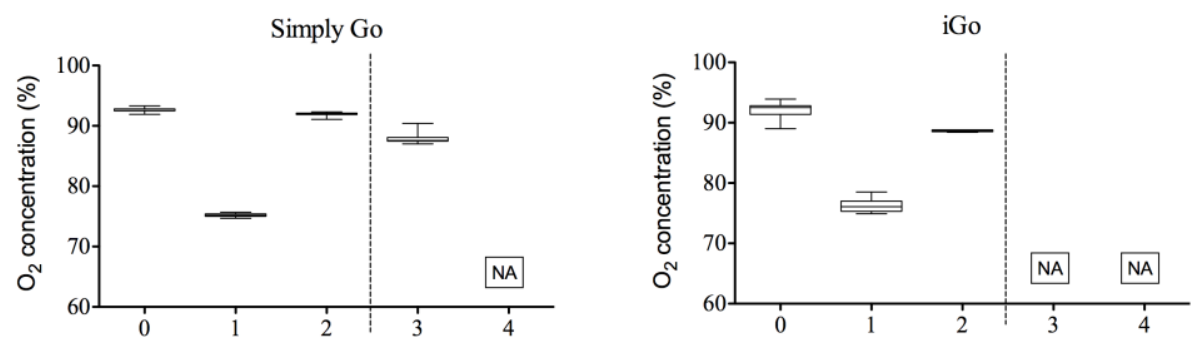

\begin{tabular}{|cl|}
\hline 0 & Patm $/ \mathrm{FO}_{2}=0.21$ \\
1 & $\begin{array}{l}\text { Normobaric Hypoxia } \\
\mathrm{FO}_{2}=0.15\end{array}$ \\
2 & $\begin{array}{l}\text { Hypobaric Hypoxia } \\
(2438 \mathrm{~m})\end{array}$ \\
3 & $\begin{array}{l}\text { Hypobaric Hypoxia } \\
(4214 \mathrm{~m})\end{array}$ \\
4 & $\begin{array}{l}\text { Hypobaric Hypoxia } \\
(8000 \mathrm{~m})\end{array}$
\end{tabular}

294
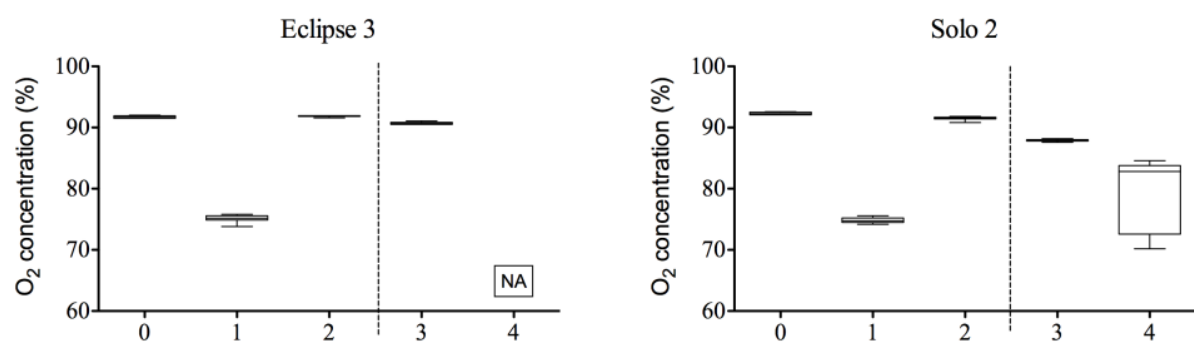

295 Figure 2: Measurement of the oxygen fraction provided by four portable oxygen

concentrators under various pressure and ambient $\mathrm{FO}_{2}$ conditions. Results expressed

297 with median and interquartile range.

298 A: SimplyGo, continuous mode, 2 1/min. B: iGo, continuous mode, 3 1/min. C: Eclipse3, 299 continuous mode, 3 1/min. D: Solo2, continuous mode, 3 1/min.

300 0: Measurement outside of the chamber/tent $\left(\mathrm{P}=1.013 \mathrm{mbar}, \mathrm{FO}_{2}=0.209\right)$; 1: Measurement 301 in the normobaric hypoxic tent $\left(\mathrm{P}=1.013\right.$ mbar, $\left.\mathrm{FO}_{2}=0.15\right) ; 2:$ Measurement in hypobaric 302 chamber $\left(\mathrm{FO}_{2}=0.209\right)$ at $753 \mathrm{mbar}(8,000 \mathrm{ft} / 2,438 \mathrm{~m})$; 3: Measurement in hypobaric 303 chamber $\left(\mathrm{FO}_{2}=0.209\right)$ at $450 \mathrm{mbar}(14,000 \mathrm{ft} / 4,214 \mathrm{~m}) ; 4$ : Measurement in hypobaric 304 chamber $\left(\mathrm{FO}_{2}=0.209\right)$ at $356 \mathrm{mbar}(26,247 \mathrm{ft} / 8,000 \mathrm{~m})$. NA: Not Applicable: inefficacy of 305 the portable oxygen concentrators to provide $\mathrm{O}_{2}$ : measured $\mathrm{FO}_{2}=0.21$. 


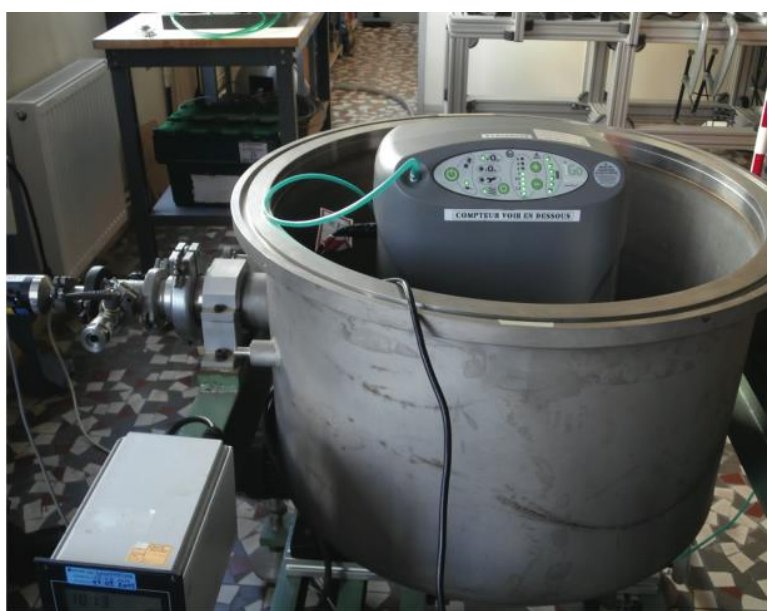

312 Supplemental figure: Set-ups used for measurements. On the left, a portable oxygen

313 concentrator in an hypoxic tent (hypoxic generator at the back of the room). On the right,

314 portable oxygen concentrator in the altitude chamber. 


\begin{tabular}{|c|c|c|c|c|c|c|c|c|c|}
\hline & Room Air 28 m & $\begin{array}{c}\text { Normobaric } \\
\text { hypoxia 2,438 m }\end{array}$ & $\mathrm{p}$ & $\begin{array}{c}\text { Hypobaric } \\
\text { hypoxia } 2,438 \mathrm{~m}\end{array}$ & $\mathrm{p}$ & $\begin{array}{c}\text { Hypobaric } \\
\text { hypoxia 4,214 m }\end{array}$ & $\begin{array}{c}\text { Hypobaric } \\
\text { hypoxia } 8,000 \mathrm{~m}\end{array}$ & $\mathrm{p}$ \\
\hline $\begin{array}{c}\text { SimplyGo } \\
\text { median [Q1-Q3] }\end{array}$ & $0.92[0.90-0.93]$ & $0.75[0.75-0.75]$ & $<0.001$ & $0.92[0.92-0.92]$ & 0,583 & $0.88[0.87-0.88]$ & $<0.001$ & NA & NA \\
\hline $\begin{array}{c}\text { iGo } \\
\text { median [Q1-Q3] }\end{array}$ & $0.93[0.91-0.93]$ & $0.76[0.75-0.76]$ & $<0.001$ & $0.89[0.89-0.89]$ & $<0.001$ & NA & NA & NA \\
\hline $\begin{array}{c}\text { Eclipse3 } \\
\text { median [Q1-Q3] }\end{array}$ & $0.94[0.95-0.96]$ & $0.75[0.75-0.76]$ & $<0.001$ & $0.92[0.92-0.92]$ & $<0.001$ & $0.91[0.91-0.91]$ & $<0.001$ & NA & NA \\
\hline $\begin{array}{c}\text { Solo2 } \\
\text { median [Q1-Q3] }\end{array}$ & $0.93[0.93-0.93]$ & $0.75[0.74-0.75]$ & $<0.001$ & $0.92[0.91-0.92]$ & $<0.001$ & $0.88[0.88-0.88]$ & $<0.001$ & $0.83[0.73-0.84]$ & $<0.001$ \\
\hline $\begin{array}{c}\text { TOTAL } \\
\text { median [Q1-Q3] }\end{array}$ & $0.93[92-94]$ & $0.75[0.75-0.76]$ & 0,029 & $0.92[0.89-0.92]$ & 0,029 & $0.88[0.88-0.91]$ & 0,0498 & $0.83[0.73-0.84]$ & NA \\
\hline
\end{tabular}

322 Table 1: Median and interquartile range of $\mathrm{O}_{2}$ concentrations produced by four

323 portable oxygen concentrators under the various conditions tested. $\mathrm{N}=30$ measurements

324 for room air, normobaric hypoxia (2,438 m) and hypobaric hypoxia (2,438 m) conditions;

$325 \mathrm{~N}=10$ measurements for hypobaric hypoxia at 4,214 $\mathrm{m}$ and 8,000 m conditions. Each hypoxic

326 condition was compared to the reference condition (room air, $28 \mathrm{~m}$ ) by a Mann-Whitney test.

327 NA: Not applicable (oxygen concentrators no longer generated $\mathrm{O}_{2}$, identical measurements

328 making comparison impossible). 